\title{
Application of a Phase-Measuring Method in the Inclinometric Systems of Geotechnical Monitoring
}

\author{
Anastasia V. Grecheneva ${ }^{1}$, Oleg R. Kuzichkin ${ }^{1}$, Nikolay V. Dorofeev ${ }^{2}$, Vladimir T. Eremenko ${ }^{3}$ \\ ${ }^{1}$ Belgorod National Research University, 85 Pobedy st., Belgorod 308015, 1155464@bsu.edu.ru \\ ${ }^{2}$ Vladimir State University named after A. G. and N. G. Stoletovs, 23 Orlovskaya st., Murom 602264, itpu@mivlgu.ru \\ ${ }^{3}$ Orel State Technical University, 29 Naugorskoe highway, Orel 302020, wladimir@orel.ru
}

\begin{abstract}
The article considers the issue of the possibility of applying the phase-measuring method in inclinometric systems of geotechnical monitoring. The main problems with use of the inclinometric systems of geotechnical monitoring. The causes, causing the occurrence of angular measurement errors. The factors affecting the accuracy of inclinometric control. A new approach of construction for inclinometric control systems with the use of digital accelerometers. This approach is characterized by using the primary data processing algorithm that is based on a phase-measuring method. The block diagram of the organization phase-measuring method of inclinometric control.
\end{abstract}

Keywords-geotechnical monitoring, phase-measuring method, inclinometric systems, measuring system, naturaltechnical systems.

\section{INTRODUCTION}

One of the main tasks for geotechnical monitoring of the natural-technical systems (NTS) is a continuous observing of deformation processes in the "geological environment -technical object" system. The task of organizing the deformation control is achieved by using of tiltmetric, deformographic, seismic and electrometric methods of geotechnical and geodynamic control [1]. The universal method of observing geodeformation processes and angular changes of technical objects parameters(defining deflections and strains bearing structures, beams, foundations and basements, the stressstrain state of structures and high-rise buildings, bridges), is a high-precision inclinometry $[2,3]$. This is stated in the regulations for organization of the geotechnical monitoring in industrial and civil construction and nuclear energy (static and dynamic monitoring of the operated nuclear facilities on STO-SRO-S 60542960 00043-2015).

At present moment the inclinometric control of geotechnical objects by means of magnetically or gyro sensors. Requirements for the accuracy and reliability of measurement data obtained with the help of modern measuring inclinometers, are very high. This is especially true for high-risk facilities, such as nuclear power facilities [4]. For example, the tolerance for deviation from the vertical for a nuclear reactor is only $0.5 \mathrm{~mm}$, when diameter equal to nearly 5 meters.

Importance of inclinometric monitoring advances for the technical objects located within multiplicative instability areas. Such areas appear due to the effect of different external disturbing factors (temperature, humidity, etc.), and climate changes can influence on activity of the disturbances. In particular, variable patterns of space heterogeneities of annual warmingcooling cycles [5] and abrupt temperature shifts within interseasonal hysteresis regularities [6] are typical for the Vladimir Region, where our experimental tests are made. Such qualitative changes in local climate dynamics introduce essential corrections in economic estimations of climate-related damages [7].

So, the earlier some degradation of a technical object is identified, the more chance to realize the corresponding compensations. In this context, the accuracy of inclinometric control can assist to prevent more emergencies at least. The aim of this work is to study a new approach for the construction of inclinometric control systems based on digital accelerometers. This approach is characterized by the use of phase-measuring method in data preprocessing and enhances the accuracy and noise immunity of the measuring system.

\section{PRECISION PROBLEMS OF INCLINOMETRIC GEOTECHNICAL MONITORING SYSTEMS}

Technical and operational characteristics of the inclinometric system is determines possibility of use in the geotechnical control in NTS. In many ways, these characteristics depend on the metrological parameters of transducers (Table I).

The main metrological parameters of the measuring systems are their measurement uncertainty [8, 9]. Presented inclinometric systems having a minimal deviation measurement accuracy (from $\pm 0,001^{\circ}$ to \pm $\left.0,01^{\circ}\right)$, however, they are achieved by reducing the measurement range (from $0,5^{\circ}$ to $50^{\circ}$ ), which is technologically inconvenient in the case of practical use (multiple systems of one class to expand the 
measurement range must be used). Accordingly, the systems having the highest measurement range (from \pm $90^{\circ}$ to $\pm 180^{\circ}$ ) are less reliable due to the high level of error (up to $1,0^{\circ}$ ).

TABLE I. METROLOGICAL CHARACTERISTICS OF INCLINOMETRIC SYSTEMS

\begin{tabular}{|c|c|c|c|}
\hline Company & $\begin{array}{l}\text { Device } \\
\text { Model }\end{array}$ & $\begin{array}{c}\text { Measuremen } \\
\text { t Range, }^{\circ}\end{array}$ & $\begin{array}{c}\text { Measuremen } \\
\text { t Error, }^{\circ}\end{array}$ \\
\hline $\begin{array}{l}\text { Research and } \\
\text { production } \\
\text { company "CONE" } \\
\text { (Moscow) }\end{array}$ & $\begin{array}{l}\text { Tilt meters } \\
\text { IN-01 and } \\
\text { IN-02 }\end{array}$ & $\pm 90 ; \pm 180$ & $0,05-1,0$ \\
\hline KYOVA (Japan) & BKJ-A & \pm 10 & $\pm 0,01$ \\
\hline $\begin{array}{c}\text { BG electric E.K } \\
\text { (Germany) }\end{array}$ & Baumer & 360 & $0,1-0,2$ \\
\hline $\begin{array}{c}\text { POSITAL } \\
\text { FRABA (USA) }\end{array}$ & $\begin{array}{c}\text { ANGUSEN } \\
\text { S } \\
\end{array}$ & \pm 30 & $\pm 0,001$ \\
\hline $\begin{array}{l}\text { TAYLOR } \\
\text { HOBSON } \\
\text { (England) }\end{array}$ & Tralyvel 6 & $\begin{array}{l} \pm 1600 \\
\text { seconds }\end{array}$ & $\pm 1-4$ seconds \\
\hline $\begin{array}{l}\text { ROCTEST } \\
\text { (Canada) }\end{array}$ & $\begin{array}{c}\text { TUFFTIL } \\
801\end{array}$ & \pm 50 & $0,0001-0,01$ \\
\hline
\end{tabular}

III. Application OF A PHASE-MEASURING MEthod IN THE INCLINOMETRIC SYSTEMS OF GEOTECHNICAL MONITORING

The operating principle of inclinometers in geotechnical monitoring systems based on the determination of deflection angles of the object from the vertical in different planes, and determination of the rotation angle relative to the reference coordinate system associated with the Earth [10]. At the same time, as the basic coordinate system, related to the non-collinear vectors, are adopted: a vector acceleration of gravity oriented orthogonally to the horizontal plane and directed towards the center of the Earth $\vec{g}$; the vector of Earth's angular velocity $\vec{\omega}$ (Fig. 1).

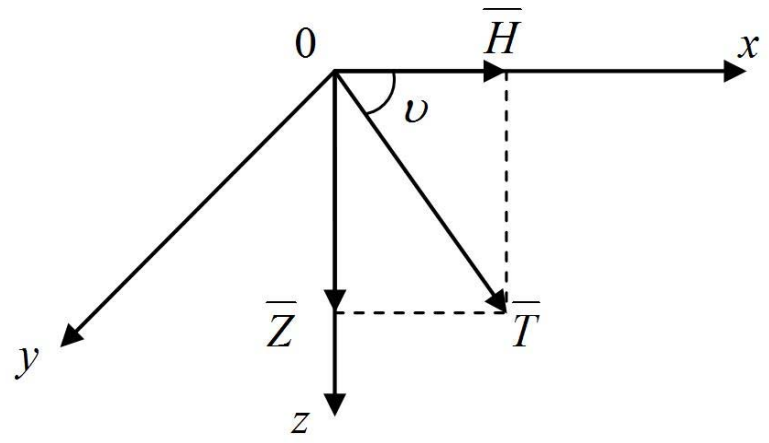

Figure 1. Basic coordinate system. $\vec{T}$ is the induction vector of the natural geomagnetic field of the Earth; $\vec{Z}$ and $\vec{H}$ are the vertical and horizontal component of vectors

According to this method, the deviation angle of the accelerometer axis on the direction of the gravitational acceleration is determined by the expression:

$$
v=\operatorname{arctg} \frac{|\vec{Z}|}{|\vec{H}|}
$$

Given a set of operating conditions, requirements imposed, measuring ranges, specifications, design features and metrological characteristics, the most promising trend in modern development inclinometric systems - is the use of the accelerometer in microelectronic execution on MEMS-technology [11]. However, the resolution capacity of accelerometric inclinometer is limited to the stability of the sensitivity factor (especially temperature stability), the accelerometric base and resistance to vibration effects $[9,12]$. The use of filtering algorithms can partially eliminate the vibration effect on angle measurement results [13]. Solution of temperature stability problems performed by using the temperature correction algorithms, for this purpose in accelerometers are inserted the temperature sensors [14]. However, even their use limits the metrological parameters accelerometric inclinometer used in geotechnical monitoring systems. Furthermore, there is a risk of error occurrence caused by the operation of division on a small value in the trigonometric arc tangent transformation [15]. The probability of such error arises in connection with the result of obtaining various values of acceleration, including close to zero.

One solution to this problem is the use of phasemeasuring method. Implementation of phase-measuring method of the rotation angle in the inclinometric control system based on the collecting dynamic data algorithm, which is based on the direct conversion of the signals from accelerometers in phase sine wave [16], by multiplying of the signals $a_{x 1}, a_{y 1}, a_{z 1}, b_{x 2}, b_{y 2}, b_{z 2}$ to signals $\sin \cdot \omega t$ and $\cos \cdot \omega t$ quadrature generator (QG) at a frequency multiple of the reference frequency generator (FG) (Fig. 2).

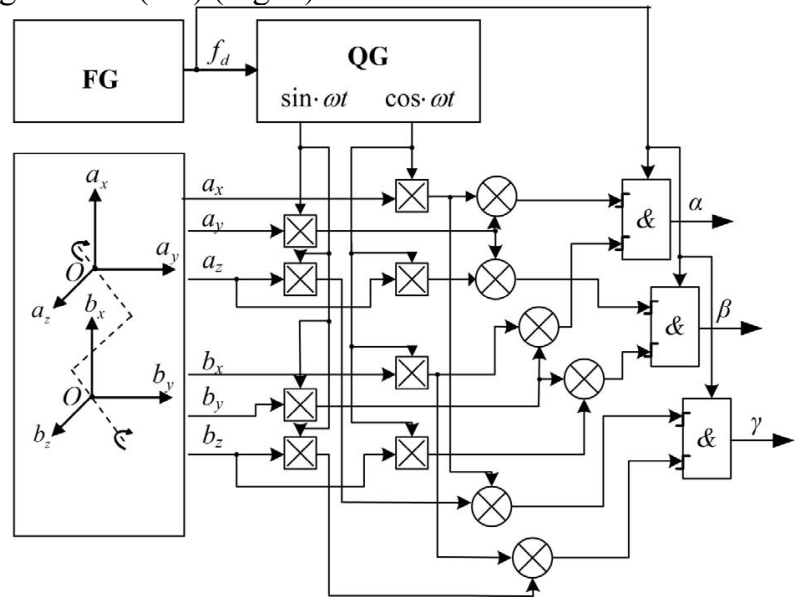

Figure 2. The scheme of algorithm of collection and pre-processing data inclinometric control 
According to the algorithm, the rotation angle in the accelerometric goniometer is determined by the phase difference between the measured and the reference signals. Therefore, a signal proportional to the angle without affecting instability coefficients transmitter branches is generated at the output by summing the received harmonic signal.

Figure 3 shows the principle of the inclinometric control with the use of accelerometer transducers and phase-measuring method algorithm. In the normal position of the control object, the acceleration values coincide with the acceleration of free fall (Figure 3a). Once the control object deviates from its normal position, between the accelerometer axes and the direction of the gravitational acceleration vector the angles $\alpha$ and $\beta$ are formed (Fig. 3b).

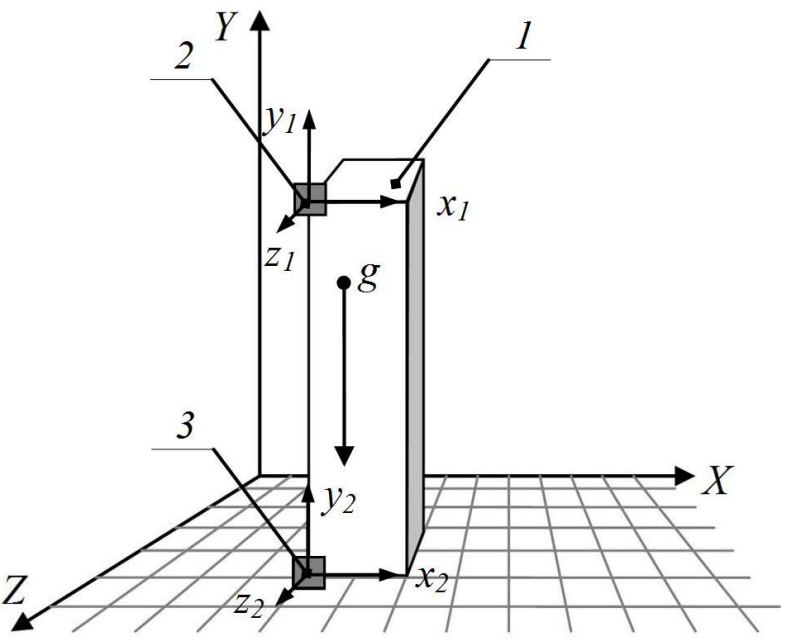

a)

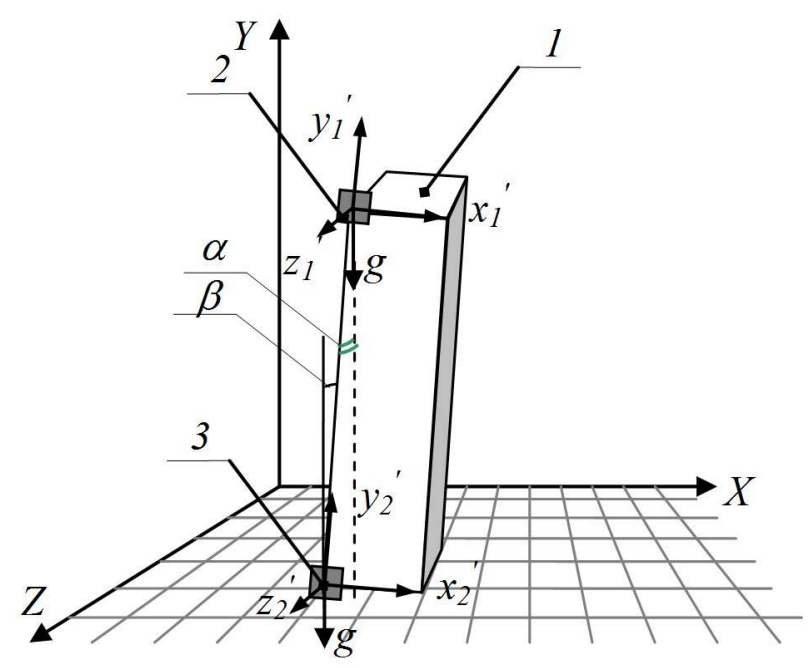

b)

Figure 3. Inclinometric control with the use of phase-measuring method. 1 is the object of control; 2.3 are the accelerometers; $\alpha, \beta$ are the angles of the control object, $g$ is the acceleration of gravity
IV. Evaluation of Metrological Parameters of THE ACCELEROMETRIC METHOD

The metrological parameters are estimated on the basis of the following equations [17]:

$$
\left\|\begin{array}{c}
U_{x} \\
U_{y} \\
Y_{z}
\end{array}\right\|=k A_{\alpha} A_{\beta} A_{\Delta} \bar{g}
$$

where $U_{x}, U_{y}, U_{z}$ are the signals from the accelerometers; $k$ is the sensitivity coefficient of the accelerometer measurements in three dimensions $k=\left\{k_{x}, k_{y}, k_{z}\right\} ; A_{\alpha} A_{\beta}$ are the tensor conversion factor at the corners $\alpha$ and $\beta ; A_{\Delta}$ is the tensor accelerometer errors for measuring unit vectors; $\bar{g}$ is the acceleration of gravity.

From (2), the errors for the standard method of accelerometer transformation (1) are determined from the expression:

$$
\begin{array}{r}
\Delta \alpha=\frac{1}{\sin \beta}\left(\sin \alpha \Delta k_{x}+\cos \alpha \Delta k_{y}\right) \\
\Delta \beta=\left[\begin{array}{l}
\left(-\cos \alpha \Delta k_{x}+\sin \alpha \Delta k_{y}\right)- \\
-\cos \beta \Delta k_{x}
\end{array}\right]
\end{array}
$$

Estimate of the temperature coefficient of error, given in [18 - 20] is $0,5^{\circ}$ when a sensitivity factor $k_{x}=0,5 \%$.

In the case of the use of phase-measuring method described in the article, the measurement error can be substantially reduced by using the following expressions:

$$
\begin{aligned}
& \Delta \alpha=\frac{\pi}{2} \cdot \frac{\Delta k_{y}-\Delta k_{x}}{\left(1+\Delta k_{y}\right) \cdot\left(1+\Delta k_{x}\right)} \\
& \Delta \beta=\frac{\pi}{2} \cdot \frac{\Delta k_{x}-\Delta k_{y}}{\left(1+\Delta k_{y}\right) \cdot\left(1+\Delta k_{x}\right)}
\end{aligned}
$$

As a result, the measurement accuracy will be significantly reduced $\Delta \alpha, \Delta \beta \approx 0,3 \cdot 10^{-2}$ degrees at $k_{x}=0,5 \%$.

\section{CONCLUSION}

Thus, application of the phase-measuring method discussed inclination increases measurement accuracy 
and eliminates the influence of the multiplicative instability arises due to the effect of external disturbing factors (temperature, humidity, etc.) As a result, the measurement error is reduced considerably and make $\Delta \alpha, \Delta \beta \approx 0,3 \cdot 10^{-2}$.

Proposed in this paper an approach would avoid the temperature and multiplicative measurement error correction and to implement the results of the measurement of information signals from accelerometers, software and algorithmic way.

\section{ACKNOWLEDGMENT}

This work was supported by a grant of the Ministry of Education and Science of the Russian Federation № 5.3606.2017/ PCH.

\section{REFERENCES}

[1] R. Sharapov and O. Kuzichkin, "Selection and partial processing geomagnetic signals in magnetotelluric observations," in Proceedings of the International Multidisciplinary Scientific GeoConference Surveying Geology and Mining Ecology Management, 2014, pp. 823-828.

[2] K. V. Slivets, "Full-scale monitoring of deformations walling experienced and excavation soil massif," Proceedings of the St. Petersburg University of Transport, no. 3, 2008.

[3] Joël Van Cranenbroeck, "State of the art in structural geodetic monitoring solutions for Hydro power dams," FIG Working Week 2011, Bridging the Gap between Cultures, Marrakech, Morocco, 18-22 May 2011, pp. 1-18.

[4] I. V. Ryzhkov, E. A. Ponomareva and E. A. Bauska, "Develop monitoring techniques of constructions of NPP," News Pdaba, no. 1-2, pp. 178-179, 2013.

[5] Yu. Kolokolov and A. Monovskaya, "Multidimensional analysis of dynamics of annual warming-cooling cycles on the basis of index model of temperature observations," in Proceedings of the $8^{\text {th }}$ IEEE International Conference on Intelligent Data Acquisition and Advanced Computing Systems: Technology and Applications, 24-26 September 2015, Warsaw, Poland, vol. 2, pp. 631-637.

[6] Yu. Kolokolov and A. Monovskaya, "Forecasting of vernal and autumnal margins in local climate dynamics," in Proceedings of the $8^{\text {th }}$ IEEE International Conference on Intelligent Data Acquisition and Advanced Computing Systems: Technology and Applications, 24-26 September 2015, Warsaw, Poland, vol. 2, pp. 570-575.

[7] Yu. Kolokolov and A. Monovskaya, "Guess-work and reasonings on centennial evolution of surface air temperature in Russia. Part IV: Towards economic estimations of climate-related damages from the bifurcation analysis viewpoint?" Int. J. of Bifurcation and Chaos, vol. 26, no. 12, 1630033, 2016.

[8] Inclinometer Posital Fraba Angusens (AGS) with can-bus interface. User manual (URL: http://www.rentamatic.ru/ms/ posital/us/products/POSITAL/AbsoluteInclinometers/AbsoluteIncl inometers_AGS_CANopen_Manual_DataContent.pdf)

[9] TUFF TILT 801 - Uniaxial Tiltmeter. User manual (URL: http://www.roctest.com/en/content/download/1085/35514/file/E50 77E-060304\%20-\%20UNIAXIAL\%20TILTMETER.pdf)

[10] N. A. Butakov "Applicability of inertial navigation systems, mobile devices," International Journal of Open Information Technologies, no. 5, pp. 24-32, 2014.

[11] A. Grecheneva, O. Kuzichkin and N. Dorofeev, "Analysis of mistakes and errors application of the accelerometric phase method of biomechanical control," in Proceedings of the 16th International Multidisciplinary Scientific GeoConference SGEM'2016, June 28-July 6, 2016, book 6, vol. 1, pp. 383-390.

[12] D. G. Milovzorov, A. S. Diachkov, "The program for calculating instrument errors converters slope parameters with the accelerometer," Certificate of official registration of the computer program № 2014616103, Moscow, RosAPO, 2014. (in Russian)

[13] O. R. Kuzichkin and N. V. Dorofeev, "Eliminating multiplicative instability of differential transducers parameters," Methods and communication devices and information processing, Radio Engineering, vol. 10, pp. 79-82, 2008. (in Russian)

[14] G. V. Milovzorov, R. A. Sultanaev, O. N. Shtanko, "Analysis and correction of instrumental errors of the tilt drive with accelerometer," Elements, devices and software, information and conversion systems: Hi. Sat-to science. RRTI works, Ryazan, 1989, pp. 79-85. (in Russian)

[15] N.V. Dorofeev, O. R. Kuzichkin, A.V. Tsaplev, "Accelerometric method of measuring the angle of rotation of the kinematic mechanisms of nodes," Applied Mechanics and Materials, vol. 770, pp. 592-597, 2015.

[16] N. V. Dorofeev, O. R. Kuzichkin and A. V. Tsaplev, "The processing unit accelerometer angle of rotation radar antenna devices," Radio Engineering and Telecommunication systems, no. 4 (16), pp. 13-19, 2014. (in Russian)

[17] G. V. Milovzorov, "Overview of the metrological basis and methodological support of the concept of checks directional converters," in Proceedings of All-Russian Scientific and Technical Conference on New methods, Technical Means and Technologies of Measuring Information, Ufa, 1997, pp. 166-167.

[18] G. N. Kovshov, "Shakeproof converter control wells zenith angle," Proceedings of the Universities. Oil and Gaz, no. 12, pp. 86-90, 1989.

[19] G. N. Kovshov, Research and Development of Electro-Directional Converters Control Systems Orientation Underground Devices, Thesis on Doctor of Tehnical Sciences degree, Ufa, 1979, 386 p. (in Russian)

[20] G. N. Kovshov, G. U. Kolovertnov, Spatial Orientation Tools of the Control Wells when Drilling, Ufa: Izd UGNTU, 2001, 228 p. (in Russian) 